\title{
Awake Prone Positioning in COVID-19 Patients
}

\author{
Prabhanjan Singh ${ }^{1}$, Prerana Jain ${ }^{2}$, Himanshu Deewan ${ }^{3}$
}

\begin{abstract}
Background:WHO has declared SARS-CoV-2 as pandemic. Patients with COVID-19 present mainly with respiratory symptoms. Prone position has been traditionally used in acute respiratory distress syndrome (ARDS) to improve oxygenation and prevent barotrauma in ventilated patients. Awake proning is being used as an investigational therapy in COVID to defer invasive ventilation, improve oxygenation, and outcomes. Hence, we conducted a retrospective case study to look for benefits of awake proning with oxygen therapy in non-intubated COVID patients.

Materials and methods: A retrospective case study of 15 COVID patients admitted from June 15 to July 1,2020 to HDU in our hospital was conducted. Co-operative patients who were hemodynamically stable and $\mathrm{SpO}_{2}<90 \%$ on presentation were included. Oxygen was administered through facemask, non rebreathing mask and non invasive ventilation to patients as per requirement. Patients were encouraged to maintain prone position and target time was $10-12$ hours/day. $\mathrm{SpO}_{2}$ and $\mathrm{P} / \mathrm{f}$ ratio in supine and prone position was observed till discharge. Primary target was $\mathrm{SpO}_{2}>95 \%$ and $\mathrm{P} / \mathrm{f}>200 \mathrm{~mm} \mathrm{Hg}$. Other COVID therapies were used according to institutional protocol.

Results: The mean $\mathrm{SpO}_{2}$ on room air on admission was $80 \%$. In day 1 to 3, the mean P/f ratio in supine position was $98.8 \pm 29.7 \mathrm{~mm} \mathrm{Hg}$ which improved to $136.6 \pm 38.8 \mathrm{~mm} \mathrm{Hg}$ after proning $(p=0.005)$. The difference was significant from day 1 to 10 . Two patients were intubated. The mean duration of stay was 11 days.

Conclusion: Awake prone positioning showed marked improvement in $\mathrm{P} / \mathrm{f}$ ratio and $\mathrm{SpO}_{2}$ in $\mathrm{COVID}-19$ patients with improvement in clinical symptoms with reduced rate of intubation.

Highlights:

- Prone position ventilation improves oxygenation by reducing VQ mismatch.

- Awake prone positioning has been used along with high-flow oxygen therapy in recent pandemic of SARS-CoV-2 virus for management of mild to moderate cases.

Keywords: Awake prone position, Coronavirus, COVID-19, SARS-CoV-2.

Indian Journal of Critical Care Medicine (2020): 10.5005/jp-journals-10071-23546
\end{abstract}

\section{INTRODUCTION}

A novel strain of coronavirus SARS-CoV-2 started from China has now spread to over 200 countries across the world. ${ }^{1,2}$ This has been declared as pandemic by the WHO. ${ }^{3}$ COVID-19 is primarily a respiratory illness. The symptoms of COVID-19 are from mild flulike illness to severe acute respiratory distress syndrome (ARDS)like requiring mechanical ventilation. ${ }^{2,3}$ The COVID-19 patients often present with low oxygen saturation requiring supplemental oxygen. However, absence of dyspnea and tachycardia is seen aptly described as "happy hypoxia". ${ }^{4-6}$

Prone ventilation is a recommended recruitment strategy in ARDS for many years in intubated patients. ${ }^{7-9}$ In recent time, awake prone position therapy has come up with great benefits. This technique improves oxygenation and decreases the need for invasive ventilation. ${ }^{10,11}$ With the global pandemic putting a strain on many countries' resources, a high-flow oxygen therapy with awake prone position seems to be of low risk, easy to perform, and low cost management strategy in non-intubated patients. ${ }^{11}$ So, we conducted a retrospective observational study in high-dependency unit (HDU) in our hospital to see the effect of awake prone position therapy in COVID-19 patients.

\section{Materials and Methods}

Approval for the study and a waiver of the consent was obtained from the institutional ethics committee. This case series describes 15 patients with COVID-19 pneumonia requiring oxygen supplementation admitted from June 15 to July 1, 2020 in HDU in
${ }^{1-3}$ Critical Care Department, QRG Hospital, Faridabad, Haryana, India

Corresponding Author: Prerana Jain, Critical Care Department, QRG Hospital, Faridabad, Haryana, India, Phone: +91 9428575114, e-mail: prerana.bjmc@gmail.com

How to cite this article: Singh $P$, Jain $P$, Deewan $H$. Awake Prone Positioning in COVID-19 Patients. Indian J Crit Care Med 2020;24(10):914-918.

Source of support: Nil

Conflict of interest: None

our hospital. All patients were diagnosed with COVID-19 disease by RT-PCR (real time-polymerase chain reaction) technique. Patients who were hemodynamically stable, $\mathrm{SpO}_{2}<90 \%$ on presentation, and able to adjust their prone position were included in the study. Those who were hemodynamically unstable, drowsy, or uncooperative were excluded from the study.

Continuous vital signs [electrocardiogram (ECG), $\mathrm{SpO}_{2}$, non invasive blood pressure (NIBP), respiratory rate, and temperature] were monitored. Intra-arterial line was inserted for frequent arterial blood gas measurement to monitor $\mathrm{PaO}_{2} / \mathrm{fiO}_{2}(\mathrm{P} / \mathrm{f})$ ratio.

Oxygen therapy was initiated with face mask at $5 \mathrm{~L} /$ minute and the flow rate was titrated to reach the target $\mathrm{SpO}_{2}>94 \%$. If the target $\mathrm{SpO}_{2}$ was not achieved then non-rebreathing mask (NRBM) at 10 to $15 \mathrm{~L}$ /minute was considered. Non-invasive ventilation (NIV) was started if respiratory distress worsened or hypoxemia not alleviated by standard oxygen therapy. Tracheal intubation and invasive ventilation were considered when the patient deteriorated, i.e., altered sensorium, hypotension, or shock. 
Awake prone position was explained to every patient and they were encouraged to spend as much time in prone position as they could tolerate. The target time in prone position was 10 to 12 hours per day. Proning was performed 1 hour after meals to avoid gastrointestinal side effects. Specific COVID-19 treatment was given to all patients according to the institutional protocol which included remdesivir, tocilizumab, dexamethasone, and low-molecular weight heparin. Target for discharging from $\mathrm{HDU}$ was $\mathrm{SpO}_{2}$ of $>95 \%$ and $\mathrm{P} / \mathrm{f}$ ratio of $>200 \mathrm{~mm} \mathrm{Hg}$. Patients were shifted to ward when they were weaned off oxygen at least for 24 hours.

\section{Results}

The mean age of the sample was 51.5 years. Eight patients had a history of systemic comorbidities like diabetes (DM) and hypertension (Htn). Only 6 patients out of 15 presented with tachypnea despite low $\mathrm{SpO}_{2}$ depicting the phenomenon of "silent hypoxemia" (Table 1).

The mean $\mathrm{SpO}_{2}$ on room air on admission was $80 \%$. Oxygen therapy was started immediately through face mask to four patients (26.6\%), NRBM to five patients (33.3\%), and NIV to six patients (40\%). Thirteen patients were successfully weaned off in mean duration of 10 days and were discharged to ward. Rest two (13\%) required invasive positive pressure ventilation (IPPV) and were shifted to intensive care unit (ICU) (Fig. 1).

$\mathrm{SpO}_{2}$ improved as soon as oxygen therapy was started. A further rise in $\mathrm{SpO}_{2}$ was seen with change in the position from supine to prone owing to the reduction in intrapulmonary shunting. This increasing $\mathrm{SpO}_{2}$ trend with prone positioning was seen in all patients (Table 2).
In first 3 days, the mean $\mathrm{P} / \mathrm{f}$ ratio in supine position was $98.8 \pm$ $29.7 \mathrm{~mm} \mathrm{Hg}$ which improved to $136.6 \pm 38.8 \mathrm{~mm} \mathrm{Hg}$ after proning ( $p$ value $=0.005$ ). Similar trend was observed over next days where mean $\mathrm{P} / \mathrm{f}$ ratio in supine position were $142.4 \pm 40.9,178.3 \pm 38.3$ and $210.3 \pm 37.9$ which increased to $173.9 \pm 46.6,214.8 \pm 44.2$, and $218.6 \pm 32.5$ from day 4 to 6 , day 7 to 10 , and day 11 to till discharge, respectively ( $p$ value $=0.050,0.033$, and 0.692). The difference was significant in the initial days from day 1 to day 10 . However, this

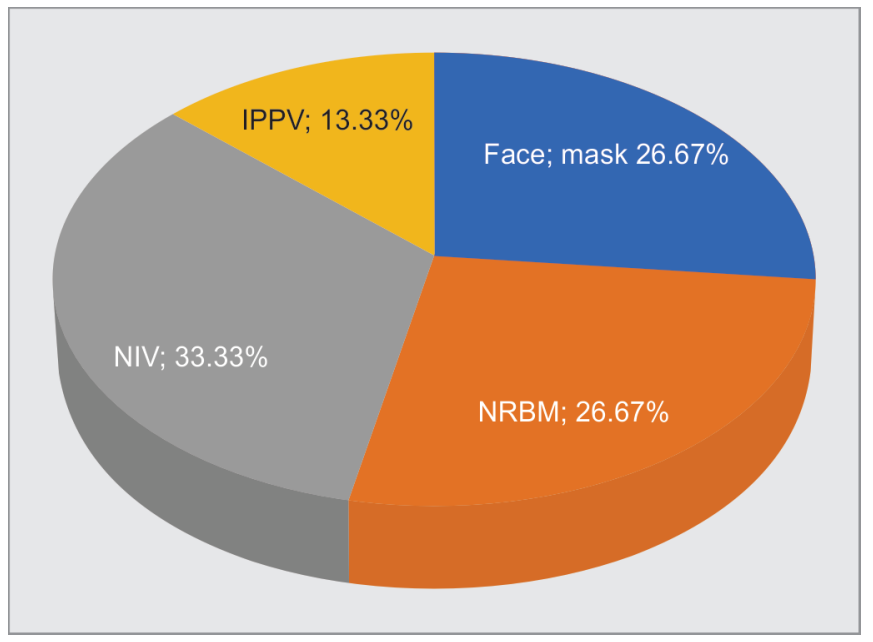

Fig. 1: Modes of oxygen therapy used for COVID-19 patients

Table 1: Overview of cases

\begin{tabular}{|c|c|c|c|c|c|c|c|c|}
\hline Caseno. & Age/gender & Comorbidities & $\begin{array}{l}\text { Room air } \\
\mathrm{SpO}_{2}(\%)\end{array}$ & Tachypnea & $\begin{array}{l}\text { Mode of oxygen } \\
\text { therapy }\end{array}$ & $\begin{array}{l}\text { Duration of } \\
\text { HDU stay (days) }\end{array}$ & $\begin{array}{l}\text { Intubation } \\
\text { required }\end{array}$ & Outcome \\
\hline 1 & $48 / \mathrm{M}$ & - & 76 & Absent & NRBM @ 15 L/minute & 10 & No & Discharged to ward \\
\hline 2 & $53 / \mathrm{M}$ & $\mathrm{DM}, \mathrm{Htn}$ & 72 & Absent & NRBM @ 15 L/minute & 13 & No & Discharged to ward \\
\hline 3 & $59 / \mathrm{M}$ & DM & 84 & Absent & $\begin{array}{l}\text { NRBM @ } 10 \text { L/minute } \\
\text { f/b NIV f/b IPPV }\end{array}$ & 20 & Yes & Expired on $D_{20}$ \\
\hline 4 & $57 / M$ & $\begin{array}{l}\text { DM, Htn, } \\
\text { obesity }\end{array}$ & 79 & Absent & NRBM@ @ 15 L/minute & 6 & No & Discharged to ward \\
\hline 5 & $58 / \mathrm{M}$ & DM & 67 & Present & NIV @ $0.8 \mathrm{FiO}_{2}$ & 9 & No & Discharged to ward \\
\hline 6 & $73 / \mathrm{M}$ & $\mathrm{DM}, \mathrm{Htn}$ & 72 & Present & $\mathrm{NIV} @ 0.7 \mathrm{FiO}_{2}$ & 12 & No & Discharged to ward \\
\hline 7 & $58 / \mathrm{M}$ & - & 88 & Present & NIV@ @ $0.8 \mathrm{FiO}_{2}$ & 15 & No & Discharged to ward \\
\hline 8 & $54 / \mathrm{M}$ & DM & 80 & Present & NIV @ $0.9 \mathrm{FiO}_{2}$ f/b IPPV & 22 & Yes & Expired on $D_{22}$ \\
\hline 9 & $57 / M$ & - & 90 & Present & NIV @ $0.6 \mathrm{FiO}_{2}$ & 14 & No & Discharged to ward \\
\hline 10 & $39 / M$ & - & 94 & Absent & $\begin{array}{l}\text { Face mask@10 L/ } \\
\text { minute }\end{array}$ & 3 & No & Discharged to ward \\
\hline 11 & $47 / F$ & - & 68 & Present & NIV @ $0.9 \mathrm{FiO}_{2}$ & 8 & No & Discharged to ward \\
\hline 12 & $67 / M$ & DM & 87 & Absent & $\begin{array}{l}\text { Face mask @ 5 L/ } \\
\text { minute }\end{array}$ & 10 & No & Discharged to ward \\
\hline 13 & $34 / \mathrm{M}$ & - & 67 & Absent & NRBM@ 15 L/minute & 7 & No & Discharged to ward \\
\hline 14 & $37 / M$ & DM & 85 & Absent & $\begin{array}{l}\text { Face mask @ } 10 \text { L/ } \\
\text { minute f/b NRBM @ } 15 \\
\text { L/minute }\end{array}$ & 10 & No & Discharged to ward \\
\hline 15 & $32 / \mathrm{M}$ & - & 89 & Absent & $\begin{array}{l}\text { Facemask@ @ L/ } \\
\text { minute }\end{array}$ & 7 & No & Discharged to ward \\
\hline $\begin{array}{l}\text { Mean } \pm \\
\text { SD }\end{array}$ & $51.5 \pm 11.9$ & - & $80 \pm 0.09$ & - & - & $10 \pm 5.13$ & - & - \\
\hline
\end{tabular}


Table 2: Median $\mathrm{SpO}_{2}$ (\%) with oxygen therapy in supine and prone positions

\begin{tabular}{|c|c|c|c|c|c|c|c|c|c|}
\hline \multicolumn{2}{|c|}{ On presentation } & \multicolumn{8}{|c|}{ Median $\mathrm{SpO}_{2}(\%)$ with oxygen therapy (Interquartile range in parenthesis) } \\
\hline \multirow[b]{2}{*}{ Cases } & \multirow[b]{2}{*}{$\begin{array}{l}\text { Room air } \\
\mathrm{SpO}_{2}(\%)\end{array}$} & \multicolumn{2}{|c|}{ Day 1-3 } & \multicolumn{2}{|c|}{ Day 4-6 } & \multicolumn{2}{|c|}{ Day 7-9 } & \multicolumn{2}{|c|}{ Day 10-till discharge } \\
\hline & & $\begin{array}{l}\text { Supine } \\
\text { positon }\end{array}$ & $\begin{array}{l}\text { Prone } \\
\text { position }\end{array}$ & $\begin{array}{l}\text { Supine } \\
\text { positon }\end{array}$ & $\begin{array}{l}\text { Prone } \\
\text { position }\end{array}$ & $\begin{array}{l}\text { Supine } \\
\text { positon }\end{array}$ & $\begin{array}{l}\text { Prone } \\
\text { position }\end{array}$ & $\begin{array}{l}\text { Supine } \\
\text { positon }\end{array}$ & $\begin{array}{l}\text { Prone } \\
\text { position }\end{array}$ \\
\hline Case 1 & 76 & $93(88-94)$ & $96(93-97)$ & $94(92-96)$ & $96(94-97)$ & $95(96-98)$ & $97(96-99)$ & 97 (97-99) & $97(96-99)$ \\
\hline Case 2 & 72 & $92(86-94)$ & $95(92-97)$ & $92(89-95)$ & $95(93-97)$ & $94(93-96)$ & $96(95-98)$ & $98(97-100)$ & $99(98-100)$ \\
\hline Case 3 & 84 & $88(85-92)$ & 91 (88-93) & $88(87-90)$ & $90(88-91)$ & 87 (86-94) & 90 (89-96) & - & - \\
\hline Case 4 & 79 & 89 (88-93) & 92 (88-94) & 93 (92-95) & $95(93-96)$ & 96 (94-97) & 97 (95-99) & - & - \\
\hline Case 5 & 67 & $85(82-90)$ & 89 (86-91) & 87 (85-90) & 90 (88-92) & 92 (91-94) & 95 (94-98) & - & - \\
\hline Case 6 & 72 & 89 (84-92) & $92(90-94)$ & 91 (89-93) & 93 (92-94) & 93 (92-95) & 94 (93-96) & $96(95-98)$ & $98(96-99)$ \\
\hline Case 7 & 88 & 92 (89-95) & 95 (93-96) & 93 (90-94) & 95 (94-96) & 95 (94-97) & 97 (96-99) & 98 (95-99) & 98 (97-99) \\
\hline Case 8 & 80 & 87 (84-91) & 89 (87-91) & - & - & - & - & - & - \\
\hline Case 9 & 90 & $94(90-96)$ & 96 (93-97) & $95(93-96)$ & $97(95-98)$ & 98 (97-99) & $99(97-100)$ & - & - \\
\hline Case 10 & 94 & 96 (95-98) & 98 (94-98) & $99(98-100)$ & $99(98-100)$ & - & - & - & - \\
\hline Case 11 & 68 & 89 (84-90) & 93 (90-94) & $92(89-93)$ & 95 (93-96) & 97 (96-99) & $99(97-100)$ & - & - \\
\hline Case 12 & 87 & 91 (88-94) & 94 (91-95) & 93 (91-95) & 96 (94-97) & 95 (94-96) & 97 (96-99) & 97 (96-99) & $98(97-100)$ \\
\hline Case 13 & 67 & $88(85-92)$ & 93 (90-94) & $92(90-94)$ & 95 (92-96) & 97 (96-99) & 99 (98-99) & - & - \\
\hline Case 14 & 85 & 90 (87-94) & 94 (89-95) & $93(92-96)$ & 96 (93-97) & 96 (95-98) & 97 (95-99) & $98(97-100)$ & $99(97-100)$ \\
\hline Case 15 & 89 & $92(90-95)$ & $95(92-96)$ & 94 (92-95) & 97 (96-98) & $99(98-100)$ & $99(97-100)$ & - & - \\
\hline
\end{tabular}

difference was insignificant after 10 days till the time of discharge (Table 3). The mean duration of stay was 10 days in HDU (Fig. 2).

Only 2 patients out of 15 required intubation in view of progressing disease or deteriorating consciousness who were excluded from the study.

\section{Discussion}

COVID-19 pneumonia is a specific disease whose distinctive features are severe hypoxemia often associated with near normal respiratory system compliance. ${ }^{12}$ Hence, an unusual phenomenon of "happy hypoxia" or "silent hypoxemia" is seen in many patients. 5 , Patients appear to be normally functioning without dyspnea and tachycardia despite being hypoxemic.

Patients with severe disease often require high oxygenation support. High-flow oxygen therapy and noninvasive positive pressure ventilation have been used. Some patients may develop ARDS and warrant invasive ventilation. ${ }^{13}$ Hence, any therapy which can improve oxygenation and reduce lung injury should be used to improve the survival rate.

The initial approach for managing such patients was to intubate early to decrease the work of breathing and prevent patient selfinflicted lung injury (P-SILI). ${ }^{12,14}$ Later on, it was found that the complications and mortality were high with this approach. ${ }^{15,16}$ Moreover, during the pandemic time, it led to resources and manpower crisis, especially in developing nations.

The role of prone position ventilation is well established in classical ARDS. ${ }^{8}$ In prone position, there is hemogeneous distribution of the gas which reduces the ventilation-perfusion (VQ) mismatch. This reduces the intrapulmonary shunt and opens the atelectatic lung areas with adequate sputum drainage, improving oxygenation. ${ }^{7,9}$ Also, the transpulmonary pressure gradient is reduced which decreases barotrauma. ${ }^{9}$

In recent studies, awake prone positioning was used in emergency department and ward settings to maintain oxygenation of COVID-19 patients. ${ }^{17,18}$ Studies have shown to avoid intubation with early application of prone positioning with high-flow nasal cannula (HFNC) in moderate ARDS patients. ${ }^{19-21}$ In our study, we also found that the median P/f ratio significantly improved from supine to prone position from day 1 to day 10 . We were able to reduce the intubation rates, avoid the problems related to invasive ventilation and with use of sedation and neuromuscular blockers. The mean duration of stay was 10 days in HDU. Two out of 15 patients who required intubation were shifted to ICU and subsequently expired.

Most patients tolerated the prone position well and reported the improvement in symptoms. We are also cognizant that other COVID-19 therapies could have modified the disease course as well. ${ }^{22-25}$ Hence, awake proning with high-flow oxygen therapy proved to be a low risk, easy to perform, easily tolerated, and low cost rescue therapy in COVID-19 patients.

\section{LiMITATIONS}

- There was no randomization to a control group.

- Sample size of the study was small.

- High-flow nasal cannula was not available in our set up which is highly recommended.

\section{Conclusion}

Awake prone positioning showed marked improvement in $\mathrm{P} / \mathrm{f}$ ratio and $\mathrm{SpO}_{2}$ in COVID-19 patients with improvement in clinical symptoms and minimal complications. We were able to reduce the intubation rates which helped in offloading the resource and manpower burden on healthcare system in pandemic. 


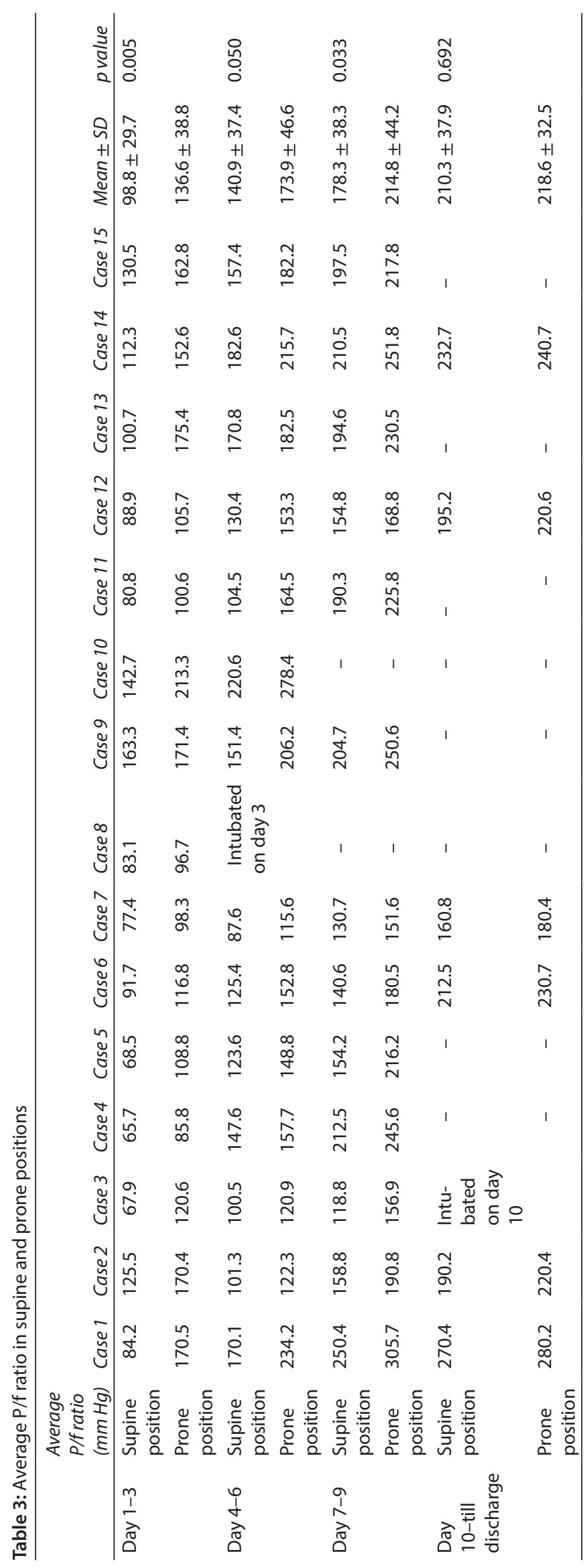




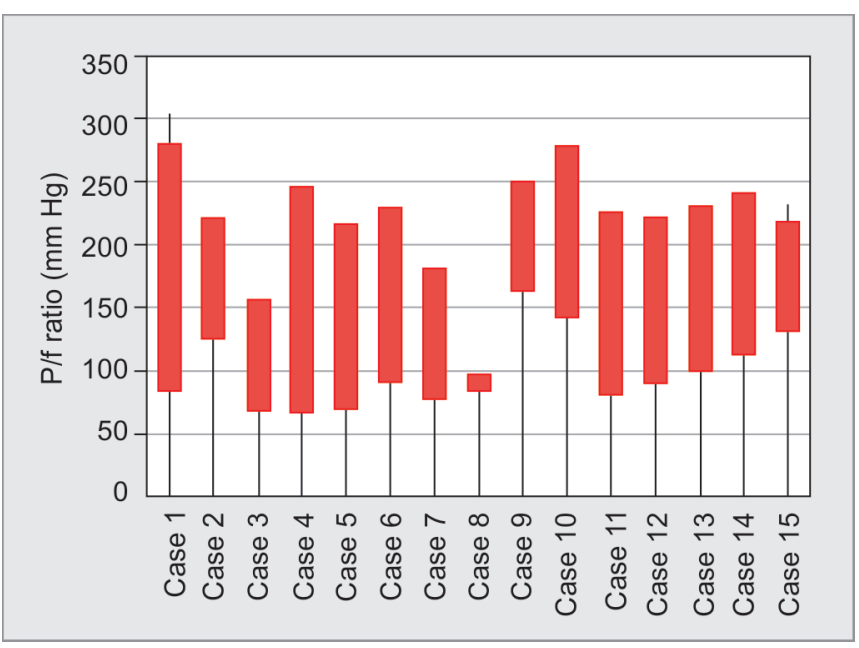

Fig. 2: Range of $P / f$ ratio in individual cases during the course of treatment

\section{References}

1. Singhal T. A review of coronavirus disease-2019 (COVID-19). Indian J Pediatr 2020;87(4):281-286. DOI: 10.1007/s12098-020-03263-6.

2. Hui DS, I Azhar E, Madani TA, Ntoumi F, Kock R, Dar O, et al. The continuing 2019-nCoV epidemic threat of novel coronaviruses to global health - the latest 2019 novel coronavirus outbreak in Wuhan, China. Int J Infect Dis 2020;91:264-266. DOI: 10.1016/j.ijid.2020. 01.009 .

3. Jain N, Choudhury A, Sharma J, Kumar V, De D, Tiwari R. A review of novel coronavirus infection (coronavirus disease-19). Glob J Transfus Med 2020;5(1):22-26. DOI: 10.4103/GJTM.GJTM_24_20.

4. Couzin-Frankel J. The mystery of the pandemic's 'happy hypoxia'. Science 2020;368(6490):455-456. DOI: 10.1126/science.368. 6490.455.

5. Tobin MJ, Laghi F, Jubran A. Why COVID-19 silent hypoxemia is baffling to physicians. Am J Respir Crit Care Med 2020(3). DOI: 10.1164/ rccm.202006-2157CP.

6. Wilkerson RG, Adler JD, Shah NG, Brown R. Silent hypoxia: a harbinger of clinical deterioration in patients with COVID-19. Am J Emerg Med 2020. S0735-6757(20)30390-9 10.1016/j.ajem.2020.05.044.

7. Koulouras V, Papathanakos G, Papathanasiou A, Nakos G. Efficacy of prone position in acute respiratory distress syndrome patients: a pathophysiology-based review. World J Crit Care Med 2016;5(2):121136. DOI: 10.5492/wjccm.v5.i2.121.

8. Guérin C, Reignier J, Richard JC, Beuret P, Gacouin A, Boulain T, et al. Prone positioning in severe acute respiratory distress syndrome. $\mathrm{N}$ Engl J Med 2013;368(23):2159. DOI: 10.1056/NEJMoa1214103.

9. Taccone P, Pesenti A, Latini R, Polli F, Vagginelli F, Mietto C, et al. Prone positioning in patients with moderate and severe acute respiratory distress syndrome: a randomized controlled trial. JAMA 2009;302(18):1977. DOI: 10.1001/jama.2009.1614.
10. Ghelichkhani P, Esmaeili M. Prone position in management of COVID19 patients; A commentary. Arch Acad Emerg Med 2020;8(1):e48.

11. Carsetti A, Damia Paciarini A, Marini B, Pantanetti S, Adrario E, Donati A. Prolonged prone position ventilation for SARS-CoV-2 patients is feasible and effective. Crit Care 2020;24(1):225. DOI: https://doi. org/10.1186/s13054-020-02956-w.

12. Marini JJ, Gattinoni L. Management of COVID-19 respiratory distress. JAMA 2020;323(22):2329-2330. DOI: 10.1001/jama.2020.6825.

13. Tobin. MJ. Basing respiratory management of COVID-19 on physiological principles. Am J Respir Crit Care Med 2020;201(11):13191336. DOI: 10.1164/rccm.202004-1076ED.

14. Gattinoni L, Chiumello D, Caironi P, Busana M, Romitti F, Brazzi L, et al. COVID-19 pneumonia: Different respiratory treatments for different phenotypes? Intensive Care Med 2020(6). DOI: 10.1007/s00134-02006033-2.

15. Tobin MJ, Laghi F, Jubran A. Caution about early intubation and mechanical ventilation in COVID-19. Ann Intensive Care 2020;10(1):78. DOI: 10.1186/s13613-020-00692-6.

16. Villarreal-Fernandez E, Patel R, Golamari R, Khalid M, DeWaters A, Haouzi P. A plea for avoiding systematic intubation in severely hypoxemic patients with COVID-19 associated respiratory failure. Crit Care 2020;24(1):337. DOI: 10.1186/s13054-020-03063-6.

17. Thompson AE, Ranard BL, Wei $Y$, Jelic S. Prone positioning in awake, nonintubated patients with COVID-19 hypoxemic respiratory failure. JAMA Intern Med 2020. e203030. DOI: 10.1001/ jamainternmed.2020.3030.

18. Caputo ND, Strayer RJ, Levitan R. Early self-proning in awake, non-intubated patients in the emergency department: a single ED's experience during the COVID-19 pandemic. Acad Emerg Med 2020;27(5):375-378. DOI: 10.1111/acem.13994.

19. Ding $L$, Wang $L, M a$ W. Efficacy and safety of early prone positioning combined with HFNC or NIV in moderate to severe ARDS: a multicenter prospective cohort study. Crit Care 2020;24(1):28. DOI: 10.1186/ s13054-020-2738-5.

20. Xu Q, Wang T, Qin X. Early awake prone position combined with high-flow nasal oxygen therapy in severe COVID-19: a case series. Crit Care 2020;24(1):250. DOI: 10.1186/s13054-020-02991-7.

21. Qin S, Haibo Q, Mao H, Yi Y. Lower mortality of COVID-19 by early recognition and intervention: Experience from Jiangsu Province. Ann Intensive Care 2020;10(1):3. DOI: 10.1186/s13613-020-00650-2.

22. Gautret P, Lagier JC, Parola P, Hoang VT, Meddeb L, Mailhe M, et al. Hydroxychloroquine and azithromycin as a treatment of COVID19: results of an open-label non-randomized clinical trial. Int J Antimicrob Agents 2020;56(1):105949. DOI: 10.1016/j.ijantimicag.2020. 105949.

23. Bonovas S, Piovani D. Compassionate use of remdesivir in Covid-19. N England J Med 2020;382(25):e101. DOI: 10.1056/NEJMc2015312.

24. Robinson. J. Dexamethasone is 'first drug' to be shown to improve survival in COVID-19. Pharmaceut J 2020;304(7938):online 10.1211/ PJ.2020.20208074.

25. Kewan T, Covut F, Al-Jaghbeer MJ, Rose L, Gopalakrishna KV, Akbik. B. Tocilizumab for treatment of patients with severe COVID19: a retrospective cohort study. E Clin Med 2020;24:100418. DOI: 10.1016/j. eclinm.2020.100418. 